\title{
The Clinical Presentations and Patterns of Management of Bowel Obstruction in Northern Saudi Arabia
}

\author{
Abdullah Fahad Al Gharbi, Muhannad Saud A. Al Shammari, Jamal Ahmed A. Al Marshadi, \\ Muteb Nasser Al Awad, Abdulkarim Ali Al Qufayi, Hamoud Khalid Al Shaya, \\ Hussain Gadelkarim Ahmed* \\ College of Medicine, University of Hail, Hail, Saudi Arabia \\ Email: ^hussaingad5@gmail.com
}

How to cite this paper: $\mathrm{Al} \mathrm{Gharbi,} \mathrm{A.F.,} \mathrm{Al}$ Shammari, M.S.A., Al Marshadi, J.A.A., Al Awad, M.N., Al Qufayi, A.A., Al Shaya, H.K. and Ahmed, H.G. (2018) The Clinical Presentations and Patterns of Management of Bowel Obstruction in Northern Saudi Arabia. Surgical Science, 9, 174-181.

https://doi.org/10.4236/ss.2018.95020

Received: April 27, 2018

Accepted: May 25, 2018

Published: May 28, 2018

Copyright $\odot 2018$ by authors and Scientific Research Publishing Inc. This work is licensed under the Creative Commons Attribution International License (CC BY 4.0).

http://creativecommons.org/licenses/by/4.0/

\begin{abstract}
Background: The prompt management of patients with bowel obstruction is essential and requires initial rapid diagnosis and therapeutic intervention. Therefore, the objective of the present study was to explore the clinical presentation and pattern of management of bowel obstruction in Northern Saudi Arabia. Methodology: About 92 files referring to patients presented with obstructive bowel conditions during the period from 2013 to 2017 were retrieved from department of surgery at King Khalid Hospital, Hail, Northern Saudi Arabia. Results: Most of cases of bowel obstruction were found in 2014, followed by 2013, 2016, 2015, and 2017 constituting 22, 20, 20, 15, and 15 cases, respectively. About 76, 52, 69, 58, 13, and 28 of the patients presented with pain, constipation, vomiting, abdominal distention, bowel sound and accompanied disease, respectively. Conclusion: Laparotomy was the most common methods of bowel obstruction management in Northern Saudi Arabia. Many patients with bowel obstruction symptoms can improve without surgical intervention.
\end{abstract}

\section{Keywords}

Bowel Obstruction, Saudi Arabia, Laparotomy

\section{Introduction}

Bowel obstruction (LBO) is an abdominal emergency with high morbidity and mortality rates if left untreated [1]. Although large bowel obstruction (SBO) is less common than small bowel obstruction, it is associated with high morbidity and mortality due to delayed diagnosis and/or treatment [2]. LBO is 4 to 5 times less frequent than small bowel obstruction ( $\mathrm{SBO}$ ) and the causes of $\mathrm{LBO}$ and 
SBO differ substantially. Colonic malignancy remains the most common cause of LBO (>60\%). Additional causes of LBO include entities such as diverticulitis, colonic volvulus, and adhesion [3]. Chronic intestinal pseudo-obstructive (CIPO) conditions are considered the most severe disorders of gut motility. They continue to present significant challenges in clinical care despite considerable recent progress in our understanding of pathophysiology, resulting in unacceptable levels of morbidity and mortality. Major contributors to the disappointing lack of progress in pediatric CIPO include a dearth of clarity and uniformity across all aspects of clinical care from definition and diagnosis to management [4].

Despite the high surgical risk, early diagnosis and treatment of the obstructive disease can lead to achieve encouraging outcomes also in extremely advanced age; an aggressive evaluation of comorbidies and the cardiorespiratory risks reduction, when possible, could be useful in improve postoperative outcomes in terms of mortality [5]. Although abdominal radiography is usually the initial imaging study performed in patients suspected of having large-bowel obstruction, it may not be sufficient to distinguish obstruction from other causes of colonic dilatation [1].

The diagnosis of bowel obstruction is based mainly on a clinical examination followed by confirmatory simple routine radiological examinations such as plain X-ray of the abdominal cavity or computed tomography (CT) [6]. Multi-detector computed tomography (MDCT) plays a key role in imaging patients presenting with acute symptoms suggestive of SBO, which helps in establishing the diagnosis, elucidating the cause of obstruction, and detecting complications, such as ischemia or frank bowel necrosis and perforation [7] [8]. However, a real surgical challenge is not a decision whether to perform a surgery, but a decision when and how to perform it [6].

However, there is a lack of literature regarding bowel obstruction from Saudi Arabia, the available studies reporting cases of colorectal carcinoma [9]. Therefore, the objective of the present study was to explore the clinical presentation and pattern of management of bowel obstruction in Northern Saudi Arabia.

\section{Materials and Methods}

This study was conducted in department of surgery at King Khalid Hospital, Hail, Kingdom of Saudi Arabia (KSA). All records referring to patients presented with obstructive bowel conditions during the period from 2013 to 2017 were retrieved. About 92 files were retried and its related data were used. All variables related to the patients were analyzed including; age, sex, pain, constipation, vomiting, abdominal distention, exaggerated bowel sounds, other accompanying disease, management and outcomes were obtained.

\subsection{Ethical Consent}

The study was approved by Ethical Review Board, College of Medicine, University 
of Hail, Saudi Arabia. This in addition to the fact that, the authors followed the tenants of the Declaration of Helsinki.

\subsection{Statistical Analysis}

For all statistical analyses including frequencies and cross-tabulations, the SPSS statistical software version 16 was used. Pearson chi square test was used and $\mathrm{P}$. values of 0.05 or less were regarded as statistically significant.

\section{Results}

This study investigated data obtained from 92 patients presented with bowel obstruction during the period from 2013 to 2017. Most of cases were found in 2014, followed by 2013, 2016, 2015, and 2017 constituting 22, 20, 20, 15, and 15 cases, respectively, as shown in Figure 1.

Out of 92 patients, 52/92 (56.5\%) were males and 40/92 (43.5\%) were females, their ages ranging from 1 month to 87 years old with a mean age of 34 years. The majority of the patients were at age group 16-30 years constituting 27 patients followed by age groups, 46+, $31-45,<5$ years and $6-15$ years representing 26, 19, 11 and 9, correspondingly, as shown in Figure 2.

With regard to the clinical presentations of the patients, about $76,52,69,58$, 13 , and 28 of the patients presented with pain, constipation, vomiting, abdominal distention, bowel sound and accompanied disease, respectively. Pain was more common among males (86.5\%) compared to females $(77.5 \%)$. Constipation was more frequent presentation among males (69\%) compared to females (40\%). Vomiting was more frequent presentation among males (78.8\%) compared to females (70\%). Abdominal distension was more frequent presentation among Females $(65 \%)$ compared to males $(61.5 \%)$. Bowel sound was more frequent

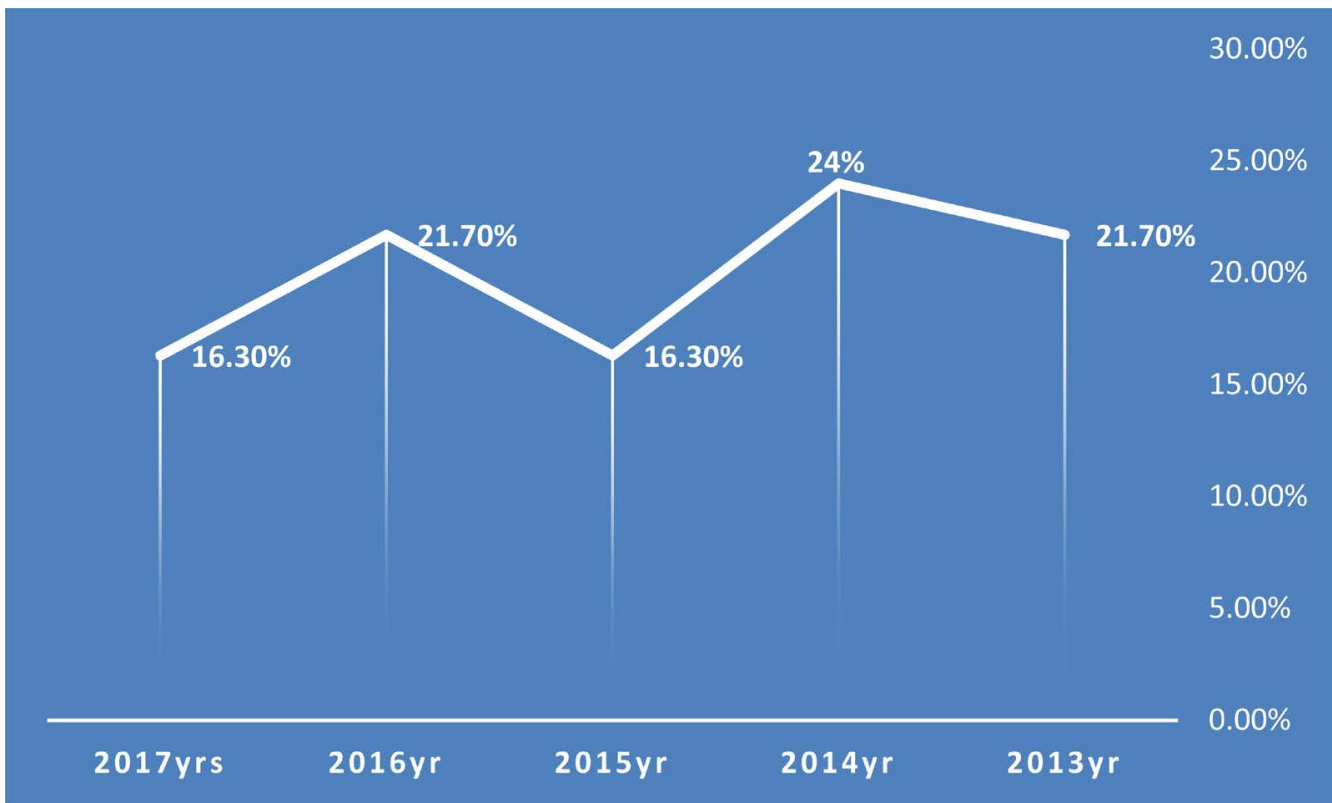

Figure 1. Description of the study population by year of presentation. 


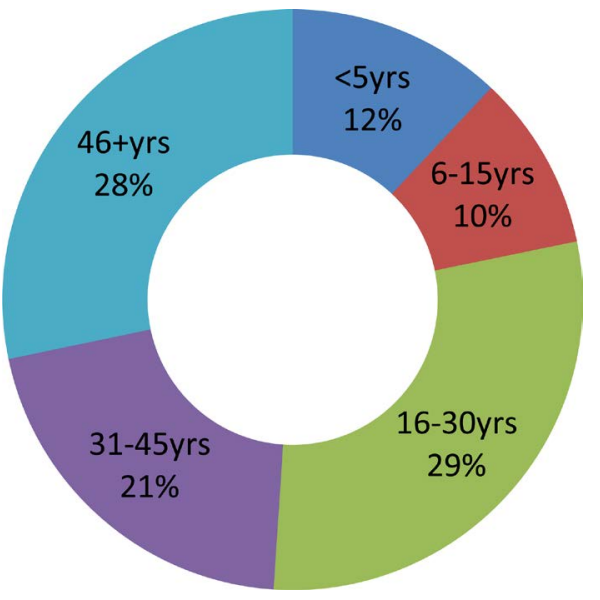

Figure 2. Description of patients by age.

Table 1. Distribution of the study population by clinical presentations.

\begin{tabular}{|c|c|c|c|c|}
\hline Variable & Category & Males & Females & Total \\
\hline \multicolumn{5}{|l|}{ Pain } \\
\hline & Yes & 45 & 31 & 76 \\
\hline & No & 7 & 9 & 16 \\
\hline & Total & 52 & 40 & 92 \\
\hline \multicolumn{5}{|c|}{ Constipation } \\
\hline & Yes & 36 & 16 & 52 \\
\hline & No & 16 & 24 & 40 \\
\hline \multicolumn{5}{|l|}{ Vomiting } \\
\hline & Yes & 41 & 28 & 69 \\
\hline & No & 11 & 12 & 23 \\
\hline \multicolumn{5}{|c|}{ Abdominal distention } \\
\hline & Yes & 32 & 26 & 58 \\
\hline & No & 20 & 14 & 34 \\
\hline \multicolumn{5}{|c|}{ Bowel sound } \\
\hline & Yes & 10 & 3 & 13 \\
\hline & No & 42 & 37 & 79 \\
\hline \multicolumn{5}{|c|}{ Other Disease } \\
\hline & Yes & 14 & 14 & 28 \\
\hline & No & 38 & 26 & 64 \\
\hline
\end{tabular}

presentation among males (19\%) compared to females (7.5\%). Other accompanied diseases were more frequent presentation among females (35\%) compared to males (27\%), as indicated in Table 1, Figure 3.

Table 2 summarized the distribution of the study population by management and outcomes. Regarding the management, most of patients underwent conservative care followed by laparotomy constituting 44/92 (47.8\%) and 38/92 
(41.3\%) respectively. Out of 44 patients underwent conservative care 27/52(52\%) were males and $17 / 40(42.5 \%)$ were females. With regard to outcomes, $71 / 92$ (\%) were improved of whom 41/52 (78.8\%) were males and 30/40 (75\%) were females, as shown in Figure 4 \& Figure 5.

\section{Discussion}

The rapid management of patients with bowel obstruction is essential and requires

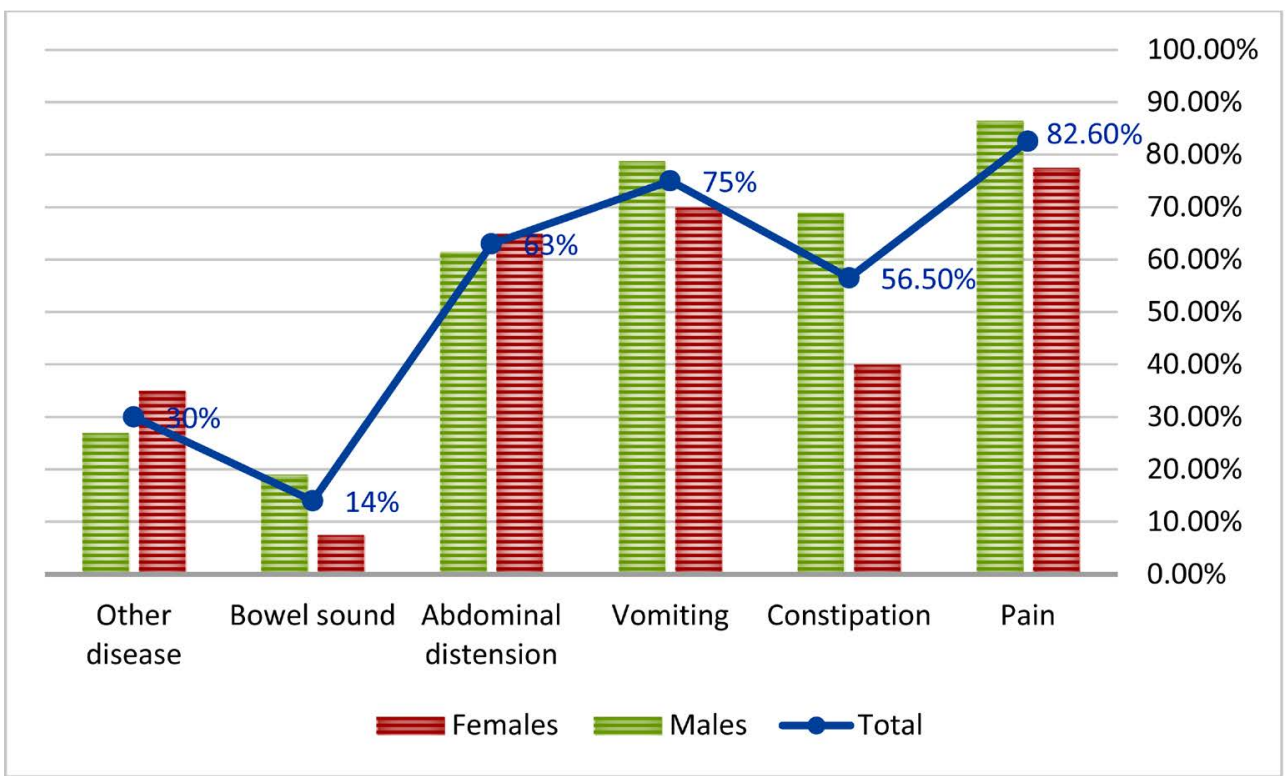

Figure 3. Description of the patients by clinical presentations

Table 2. Distribution of the study population by management and outcomes.

\begin{tabular}{ccccc}
\hline Variable & Category & Males & Females & Total \\
\hline Management & Laparotomy & 18 & 19 & 38 \\
Conservative & 27 & 17 & 44 \\
DAMA & 5 & 3 & 8 \\
Colonoscopy & 1 & 1 & 2 \\
Total & 52 & 40 & 92 \\
Outcomes & & & 71 \\
& Improved & 41 & 30 & 3 \\
& Conservation & 1 & 2 & 2 \\
Cured & 1 & 1 & 5 \\
& DAMA & 3 & 2 & 6 \\
& Complicated & 4 & 2 & 5 \\
Died & 2 & 3 & 92 \\
& Total & 52 & 42 & \\
\hline
\end{tabular}




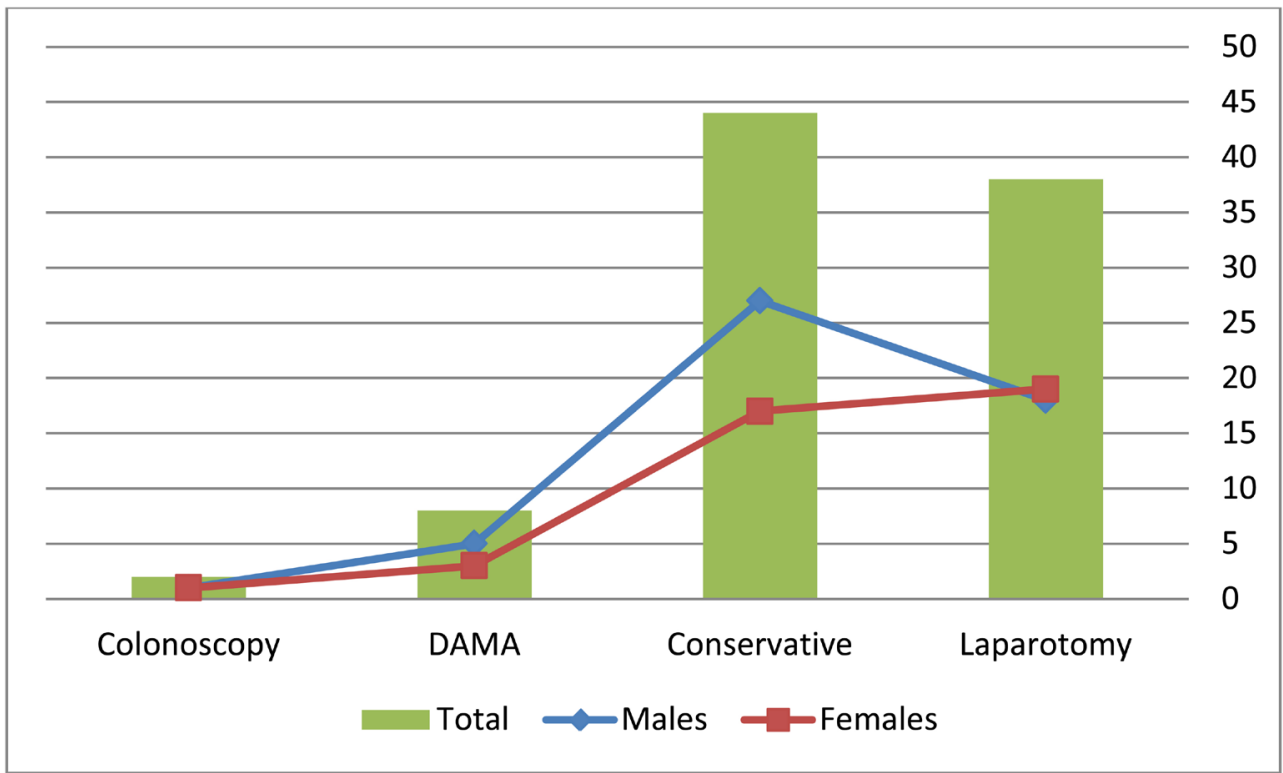

Figure 4. Description of the study population by management.

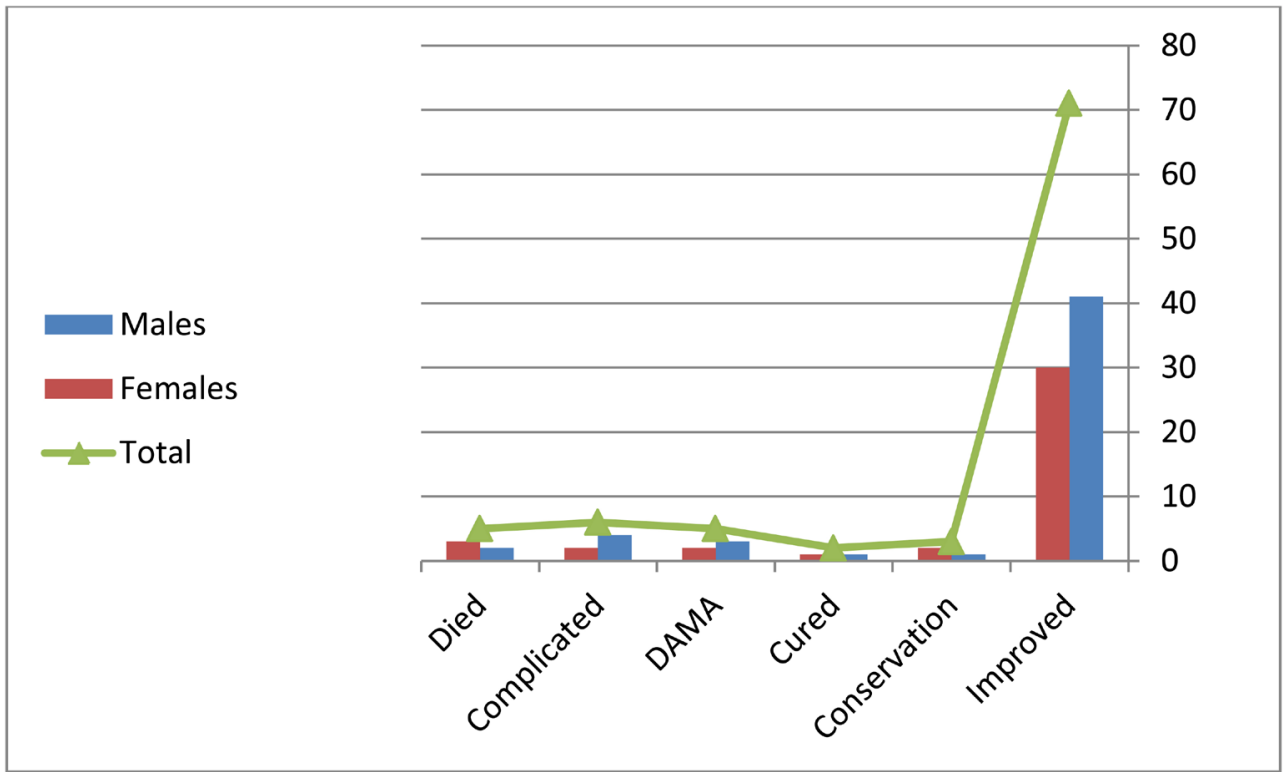

Figure 5. Description of the study population by outcomes.

initial rapid diagnosis and therapeutic intervention. The routine management measures depend, to some extent, on possible causes of obstruction relaying to some extent on the clinical presentations. The management may depend on the pattern of obstruction and is not always associated with a need to perform an emergency surgical procedure.

In the present study we focused on the clinical presentations and patterns of bowel obstruction and subsequent management. With regard to the clinical presentations, the majority of patients presented with abdominal pain, constipation, vomiting, abdominal distention, and bowel sound, gradually more, in this order. Such clinical presentations were previously reported [10]. However, bowel 
obstruction has complex symptoms, wide clinical presentations, diverse etiologies, and global geographical variations. Thus, the pattern of bowel obstruction is depend upon several factors including environmental, cultural, dietary, demographic factors, variations in the level of sophistication of the local medical services as well as individuals' anatomic differences [11] [12].

Our current findings show that bowel obstructions are more commonly among males compared to females. Such findings were previously reported in numerous studies [10] [13] [14].

In the present study about $41.3 \%$ of the patient underwent laparotomy. A decision regarding a surgical intervention is made dynamically, considering the patient's general condition, the probable cause of obstruction, as well as the intensity and dynamics of its symptoms. In extreme cases, such as cases with coexisting ischemia and secondary intestinal gangrene, a surgical intervention introduced at the appropriate time may even affect the patient's survival [6]. Laparotomy was the most common methods of intestinal obstruction management. Bowel resection and anastomosis was the commonest intra-operative procedure done and is associated with postoperative complications [15]. Over the last century there have not been significant changes in the anatomical location of obstruction. The age of presentation has increased along with age related co-morbidity. Management has consequently been challenging as risks keep on increasing with advanced age. Hence, clear decision making has become essential in its management [16].

On the other hand, the overall outcome of patients admitted with bowel obstruction is good, which may indicate better health service and good facilities at emergency settings.

\section{Conclusion}

Laparotomy was the most common methods of bowel obstruction management in Northern Saudi Arabia. Many patients with bowel obstruction symptoms can improve without surgical intervention. Good facilities at emergency settings can progressively improve the outcomes of patients with bowel obstruction.

\section{Acknowledgements}

Authors would like to thank people at the department of Surgery at King Khalid hospital, Hail, Saudi Arabia, for their help in data collection.

\section{References}

[1] Jaffe, T. and Thompson, W.M. (2015) Large-Bowel Obstruction in the Adult: Classic Radiographic and CT Findings, Etiology, and Mimics. Radiology, 275, 651-663. https://doi.org/10.1148/radiol.2015140916

[2] Ramanathan, S., Ojili, V., Vassa, R. and Nagar, A. (2017) Large Bowel Obstruction in the Emergency Department: Imaging Spectrum of Common and Uncommon Causes. Journal of Clinical Imaging Science, 7, 15.

https://doi.org/10.4103/jcis.JCIS_6_17 
[3] Yelisetti, R., Awad, A., Ambreen, B., Zijoo, R. and Wallach, S. (2017) Pharmacobezoar: An Unusual Cause of Large Bowel Obstruction. Gastroenterology Research, 10, 315-317. https://doi.org/10.14740/gr871w

[4] Thapar, N., Saliakellis, E., Benninga, M.A., et al. (2018) Paediatric Intestinal Pseudo-Obstruction: Evidence and Consensus-Based Recommendations from an ESPGHAN-Led Expert Group. Journal of Pediatric Gastroenterology and Nutrition, Mar 22. https://doi.org/10.1097/MPG.0000000000001982

[5] Oldani, A., Gentile, V., Magaton, C., et al. (2018) Emergency Surgery for Bowel Obstruction in Extremely Aged Patients. Minerva Chir. Apr 13.

[6] Szeliga, J. and Jackowski, M. (2017) Laparoscopy in Small Bowel Obstruction-Current Status-Review. Videosurgery and Other Miniinvasive Techniques, 12, 455-460. https://doi.org/10.5114/wiitm.2017.72330

[7] Pongpornsup, S., Tarachat, K. and Srisajjakul, S. (2009) Accuracy of 64 Sliced Multi-Detector Computed Tomography in Diagnosis of Small Bowel Obstruction. Journal of the Medical Association of Thailand, 92, 1651-1661.

[8] O’Malley, R.G., Al-Hawary, M.M., Kaza, R.K., Wasnik, A.P., Platt, J.F. and Francis, I.R. (2015) MDCT Findings in Small Bowel Obstruction: Implications of the Cause and Presence of Complications on Treatment Decisions. Abdominal Imaging, 40, 2248-2262. https://doi.org/10.1007/s00261-015-0477-x

[9] Albalawi, I.A., Abdullah, A.A. and Mohammed, M.E. (2017) Emergency Presentation of Colorectal Cancer in Northwestern Saudi Arabia. Saudi Medical Journal, 38, 528-533. https://doi.org/10.15537/smj.2017.5.17719

[10] Akrami, M., Ghaeini Hesarooeih, A., Barfei, M., Zangouri, V. and Alborzi, Z. (2015) Clinical Characteristics of Bowel Obstruction in Southern Iran; Results of a Single Center Experience. Bulletin of Emergency \& Trauma, 3, 22-26.

[11] Wilson, M.S., Ellis, H., Menzies, D., Moran, B.J., Parker, M.C. and Thompson, J.N. (1999) A Review of the Management of Small Bowel Obstruction. Members of the Surgical and Clinical Adhesions Research Study (SCAR). Annals of The Royal College of Surgeons of England, 81, 320-328.

[12] Akigun, Y., Yilmaz, G. and Akbayin, H. (2002) Causes and Effective Factors on Mortality of Intestinal Obstruction in the South East Anatolia. Turkish Journal of Medical Sciences, 32, 149-154.

[13] Ojo, E., Ihezue, C., Sule, A., Ismaila, O., Dauda, A. and Adejumo, A. (2014) Aetiology, Clinical Pattern and Outcome of Adult Intestinal Obstruction in Jos, North Central Nigeria. African Journal of Medicine and Medical Sciences, 43, 29-36.

[14] Malik, A.M., Shah, M., Pathan, R. and Sufi, K. (2010) Pattern of Acute Intestinal Obstruction: Is There a Change in the Underlying Etiology? Saudi Journal of Gastroenterology, 16, 272-274. https://doi.org/10.4103/1319-3767.70613

[15] Soressa, U., Mamo, A., Hiko, D. and Fentahun, N. (2016) Prevalence, Causes and Management Outcome of Intestinal Obstruction in Adama Hospital, Ethiopia. BMC Surgery, 16, 38. https://doi.org/10.1186/s12893-016-0150-5

[16] Pujahari, A.K. (2016) Decision Making in Bowel Obstruction: A Review. Journal of Clinical and Diagnostic Research: JCDR, 10, PE07-PE12.

https://doi.org/10.7860/JCDR/2016/22170.8923 